共角直径及常小于 2 "。而南京地区的大气閃㮡 常 常淹没 2" 以下的細节。所以只能在早展日出之后 二、三小时得到它的光鳍。拍得之后短时間內就消 失了。

2.大爆发日珥：这次懪发是我們拍得的爆发日 珥光粸中最强烈的一头。它于 1959 年 6 月 11 日下 午 4 时出現于太阳西南边線，当我們摄得它时已在 下降阶段。此时大气情况很差，边格馠糊。而规建与 日面奻妳交角很大，扭曲和散射都大。图 3 是它的 光籍之一，从图中可以看出，它的克度已超出或接

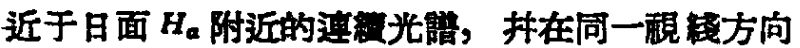
有不同的流动; 它的相对速度为 110 公里/秒。

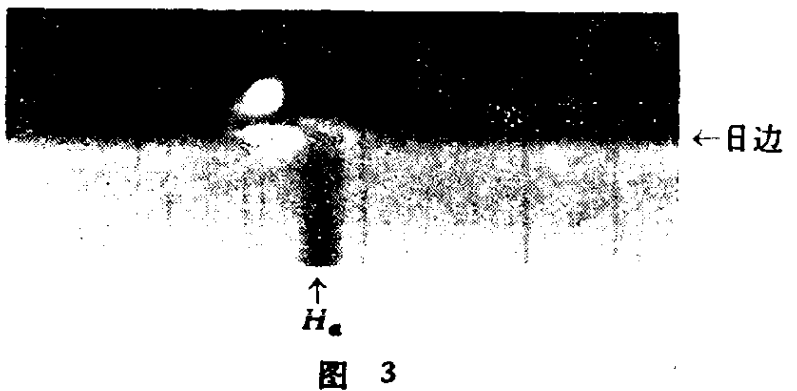

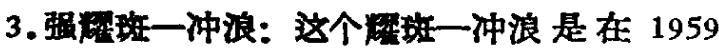
年 11 月 30 日拍得的。其特点是高速度及大牛寛 （图 4)。由諳戴位移測得最大执射速度为 450 公

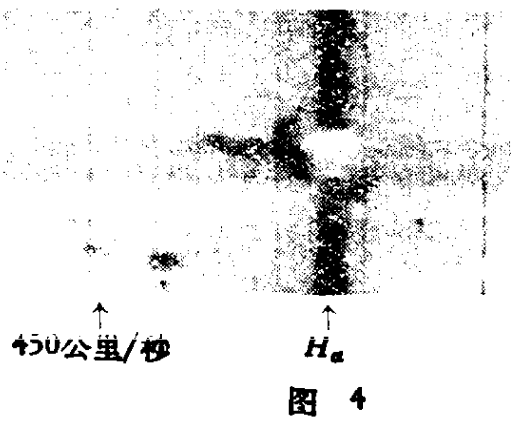

里/秒；而其最大 $H_{a}$ 譜綪牛宽为 $1.8 \AA$ ，其內部发光 源于运动平均速度为 49 公里/秒。这不可能旧之于 热运动，而只能旧之于內部的湍流。因此，我們可 以断定，不論耀珓或冲浪，均有强烈的湍流。

中国科学院紫金山天文台太陽組

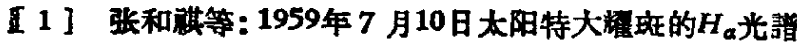
分析，天文学报，第 7 卷第 2 期 (1959.12.)。

\section{用測定能旦消耗的方法 研究金筬疲劳微裂檤}

随着近代工业和技术越来越朝着高速的方向发 展，由于交变载荷和振动所产生的疲劳失敗也就变 得越为突出，因而金属疲劳的研究和解决具有重要 的国民經济意义。

根据生产实践上的經驗，劳动人民已經能够利 用听觉和視觉来偵查和預防疲劳失敗。例如鉄路工 人便释常通过敲打和听的方法来查知材料和机件內 所已纉出現的、足以引起疲劳失敗的裂健。在总結 型众的經驗和創造的基础上，人們应該能够通过系 統的研究，找出可靠的、灵敏的扑且有理論根据的 查知疗劳微裂鍵的方法。目前所通用的超声波探 伤、X-射䋐探伤、r一射接探伤和磁性探伤等方法 只能偵知較大的裂煡，我們企图根据在疲劳过程中 的能量消耗的測量来研究疲劳裂的形成，而且找 出能够偵知較小的微裂鍵的方法。下面报导关于这 方河所进行的一些初步工作。

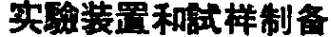

我們进行疲劳試驗所用的等是一架微型的扭 轉波劳試驗机，扭轉頻率是每分鈡 1,500 次，另外 还有每分鈡㡒环一次的慢速装䈯。用快速壮置进行

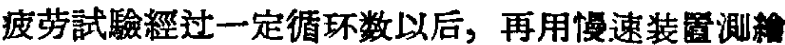
扭矩一扭角迟滞迴綫，如图 1 所示。为了驗証扭轎 速度对于迟滞迥綪的形状排没有影响，在用慢速

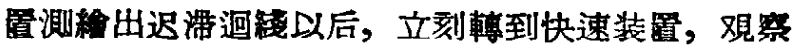
到光点所勾画出来的迥綫形状与慢速时相同。

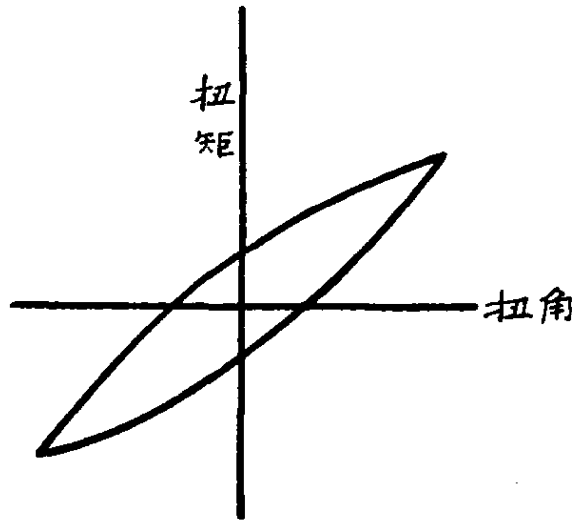

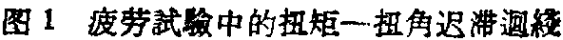


由迴的面积可以求出每次循环所消耗的能量 $\Delta E$ 由迴栈的横坐标确定出最大的扭角以后，根据 試样的尺寸, 可算出相对扭形变 $r$, 从而計算出外 加的最大切应力。由迴的秋坐标可以定出最大扭 矩 $M_{m}$, 从而求出試驗的最大切抗应力 $\tau_{m}=M_{m} / W$, $W$ 是扭轉截面系数，对于园截面試驗来證等于 $0.2 d^{3}, d$ 是試样的直径。

所用的試样是用 $99.6 \%$ 的鋁制成的。試样的 中間部分长度 10 毫米, 直径 2 毫米，两头部分各 长 7 毫米，直径 3.5 毫米。磨去試样上各处的稜角 以后，在 $450^{\circ} \mathrm{C}$ 退火一小时，这样所得到的晶粒大 小約为 0.05 毫米。經过細致的电解磨光以后，将

\section{試样装入疲劳試驗机上进行驗試。}

\section{疲劳試驗过程中的能量消耗变化}

我們在进行一系列疲劳試驗中所创括的外加应 力范围是从 3.10 到 16.55 公斤 $/$ 毫米。这个应力 范围包括低于鋁的耐久极限的应力，也包括大于鋁 的屆服应力的应力。图 2 所示的是在各种外加应力 下的能量消耗 $\Delta E$ 一循环数 $N$ 曲綫。由图可見，当 外加应力在 9.45 公斤/毫米以下时, $\Delta E-N$ 曲 綪可以分成三个阶段。在第一个阶段內, $\Delta E$ 降低; 在第二个阶段內， $\Delta E$ 基本上保持不变; 在第三个 阶段內, $\Delta E$ 睬然下降一直到試样断裂。根据一般 的趋势来看, 外加应力越大, 則各个阶段越向較低 循环数的方向移动; 同时, 能量的消耗也越大。

当外加应力超过 9.45 公斤/事米 2 时，一个显 著的不同点是， $\Delta E$ 在第一个阶段內扑不是下降，

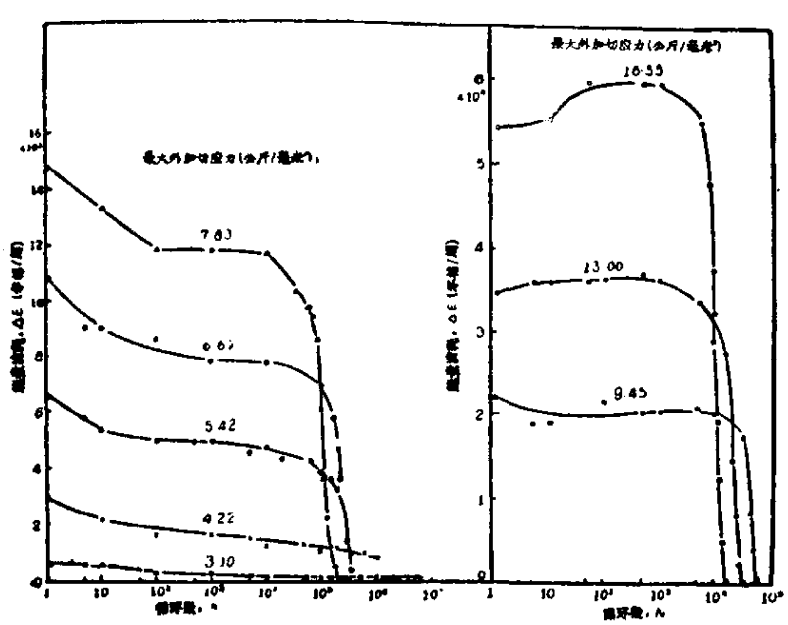

图2 鋁在各种外加扭轉应力下的能量消耗, $\Delta E$ 一䛇环数 $N$ 曲綫
而是上升。

\section{疲劳試驗过程中埾大切抗血力的变化}

在疲劳过程中，迟滞迴䋐(图 1)不仅发生面 积 和形状的变化，迴綫两极点的㭿坐标 (垖最大扭矩 $M_{m}$ ）也随着循环数 $N$ 的增加而发生变化。这意味 着, 虽然外加的应力是恆定的 (扭角在試驗过程中 不变)，但由于試样在疲劳試驗过程中发生了內 部 变化, 所以試样材料的切抗应力却不断地发生变 化。图 3 所示的是一系列的最大切抗应力 $\tau_{m}$ 随着 循环数 $N$ 而变化的曲綫。由图可見，这些曲綫也可 以分成三个阶段。在第一个阶段， $\tau_{m}$ 升高(对于所 有的外加应力来說都是如此); 在第二个阶段， $\boldsymbol{\tau}_{\boldsymbol{m}}$ 基本上保持不变; 在第三个阶段， $\boldsymbol{r}_{m}$ 躁然下降直 到試样断裂。由于最大切抗应力的增加表示試样中 发生硬化, 所以最大抗应力随着循环数而变化的情 形出表示試样的硬化随着循环数而变化的情形。

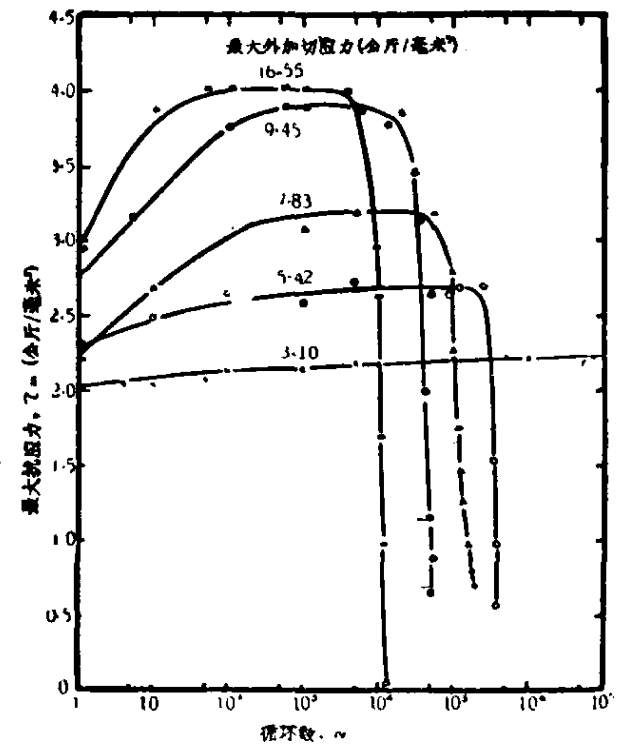

图 3 鋁在各种外加扭䡠应力下的最大抗切应力, $\tau_{m}$ 一一揩环数 $N$ 曲䋐

\section{疲劳試驗过程中的金相覌案}

对应着能量消耗 $\Delta E$ 和最大抗应力 $\tau_{m}$ 随着循 环数 $N$ 而变化的各个阶段，我們进行了試样表面的 金相覌察，以探索金相变化与三个阶段的联系。覌 察結果表明，在相当于上述第一阶段的范围內，看 不出試样表面上有任何变化的痕迹(放大 500 倍); 在进入第二阶段以后，試样表面某些局部地区出現 細滑移，随着疲劳过程的継螋，滑移綫变粗变长， 
林且有明显的局部化。为便于覌察裂样的产生和才” 展，我們在試样进行过一定的疲劳循环数以后，不 断地把試样的表面加以电解嘫光，以消除滑移痕迹 对于裂秤的掩盖。由所覌測的裂㥞长度与循环数的 关系曲綫可以看出(用外推法)，在进入第二阶段后 不久,微裂栍就已形成 (远在金相显微鏡所能覌測出 来以前)。同时始可以看出，第三阶段对应着裂 的迅速扩展，这时裂偻开始沿着垂直于試样軸綫的 方向扩展 (横展)，使試样的有效断面迅速地減小。

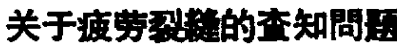

根据图 2 所示的結果，在 $\Delta E-N$ 曲綫上出現 两个轉折点：（1）在循环数 $N$ 較大时的轉折点，这 时 $\Delta E$ 由保持不变而迅速降低。与金相覌察的 結 果作比較来看, 这个轉折点表示疲劳裂链已經开始 沿径向（垂直于軸綫的方向）扩展，使試样的有效断 面制弱，因而試样的最大切抗应力 $\boldsymbol{\tau}_{m}$ 也由保持不 变而迅速降低 (見图 3)。在此轉折点出現后不久， 試样垖发生断裂，因而这个轉折点的出現是应該換 用新部件的訊量。(2) 在循环数 $N$ 較小时的轉折 点, 这时 $\Delta E$ 由逐漸降低（或逐漸升高）而保持不 变，表示微裂榷正在 开始形成，从图 3 所示的 $\tau_{m}-N$ 曲綫来看，这表示試样內部由逐漸硬化加 深而轉到不再継䋶硬化，因而在此时还可以用适当 处理的方法来消灭裂样或阻止裂艇的进一步发展， 所以这个轉折点的出現是必須对試样进行預防处理 的最后警告。

上述关于在 $\Delta E-N$ 曲綫上出現两个轉 折点 的現和推論是否也适用于弯曲式和推拉式的疲劳 試驗，还有待进一步的㸴究。

为了进一步探討能否通过測定在波劳过程中的 能量消耗变化的方法，来实际偵查試样中的疲劳裂 我們又用声頻內耗(横振动)装置測定了試样經 过一定循环数以后的內耗变化。所得的初步結果表 明，裂繾的出現及其扩展引起內耗的急剧变化。近 年来，苏联科学工作者在这方面进行了一些探索工 作，得出了不少具有启发性的結果。 ${ }^{[1,2]}$ 可以料想， 基于这一原理, 可以建立一种比目前的探伤器更为 灵敏而可靠的检查疲劳微裂繾的仪器。

此外，根据在疲劳过程中第一阶段的內耗和由 第一阶段过渡到第二阶段时的內耗变化情况，結合
試样的硬化和硬化的变化情况，也可以了解位錯的 聚龍，从而形成疲劳微裂敕的机构。关于这方面的 工作将另行报导。

参加本項工作的还有郑綿綿和潘立河两同志。

$$
\begin{gathered}
\text { 王中光 葛庭燧 } \\
\text { (中国科学院金属研究所) }
\end{gathered}
$$
1960 年 11 月 7 日

[1] С. О. Цобкалло, Сборник "Релаксационные явления в металлах и сплавах" (металлургиздат, Москва, 1960), 222 頁.

[2] И. В. Навроцкий, Ю. С. Томенко, В. Р. Голик, В. А. Дубров, 同 $[1], 316$ 面.

\section{中国主要断裂构造系統 的应力分析}

根据模拟試驗和野外覌察，岩石破碎常导因于 剪力破裂面。这些剪力破裂面常成两組出現，相交 呈 $\mathrm{X}$ 型; 但常由于旅轉应力和非均匀应变关系,一組 常比另一組发育为好。挤压力作用方向常对着所形 成的 $\mathrm{X}$ 型剪力面所夹的銳角。在向斜內， $\mathrm{X}$ 型剪力 面所夹的銳角对着压力作用方向;而在背斜內,則其 所夹的鈍角对着压力作用方向，因为后者所形成的 $\mathrm{x}$ 型剪力面是由弯曲作用引起的张力而形成的。

在模拟試驗过程中，我們还可以看出：当試驗 标本受挤压佁未形成譛曲时，先产生两組交义呈 $\mathrm{X}$ 型的前力面，所夹銳角对着压力作用方向。如継綪 加大挤压力而試驗标本仍不能形成裮曲时，則由挤 压作用在其垂直方向所引起的张力作用开始率就 $\mathrm{X}$ 型䙷力面以形成横向 (垂直于标本长軸) 鋸齿状张力 断裂。如試驗标本受挤压形成整曲时，在背斜部分 因弯曲作用形成 $\mathrm{X}$ 型剪力面，所夹鈍角对着原挤压 力作用方向，随着弯曲作用的加强，于是在后期漳 就这些 $\mathrm{X}$ 型剪力面而形成級向 (年行于背斜軸)鋸断 状张力断裂; 在向斜部分，除初期形成的以銑角对 着原挤压力作用方向的 $\mathrm{X}$ 型剪力面外，还在后期随 着原挤压作用的加强率就这些盼力面形成横向（垂 直于向斜軸）鋸实状张力断裂。我們曾把张力断裂 导源于剪力面的作用叫作断裂的率就，現在李四光 数授則名之曰断裂的追踪。 